\title{
Diprophylline inhibits non-small cell lung cancer A549 cell proliferation and migration, and promotes apoptosis, by downregulating PI3K signaling pathway
}

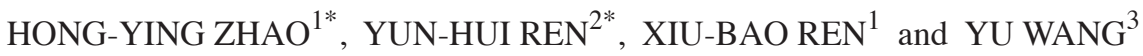 \\ ${ }^{1}$ Department of Oncology, Tianjin Medical University Cancer Institute and Hospital, Tianjin 300060; \\ ${ }^{2}$ Department of Oncology, Daqing Longnan Hospital, Daqing, Heilongjiang 163453; ${ }^{3}$ Department of Oncology, \\ Xuzhou Cancer Hospital, Xuzhou, Jiangsu 221000, P.R. China
}

Received January 12, 2018; Accepted October 3, 2018

DOI: $10.3892 / \mathrm{ol} .2018 .9678$

\begin{abstract}
Diprophylline (DPL) is identified as a methylxanthine (MX) derivative. A number of MX derivatives are reported to have anti-tumor effects. However, it is not clear whether DPL has a therapeutic effect on non-small cell lung cancer (NSCLC). The aim of the present study was to investigate the effects of DPL on NSCLC and to elucidate the potential underlying mechanism. A Cell Counting Kit- 8 assay was used to evaluate the potential effect of DPL on A549 cell proliferation. Transwell invasion and migration assays were performed to assess the effect of DPL on A549 cell migration and invasion. Furthermore, the percentage of apoptotic cells was detected by flow cytometric analysis, and proteins associated with apoptosis, including apoptosis regulator $\mathrm{Bcl}-2$, apoptosis regulator BAX and active caspase-3, were examined by western blotting. Finally, the expression levels of molecules relevant to phosphoinositide 3-kinase (PI3K) signaling were detected by western blot analysis. The present study demonstrated that DPL may significantly inhibit A549 cell proliferation, migration and invasion. Furthermore, treatment with DPL may significantly induce A549 cell apoptosis. Finally, the protein expression levels associated with the PI3K signaling pathway were significantly inhibited in A549 cells following treatment with DPL. In conclusion, DPL may inhibit the proliferation and migration of NSCLC by inactivating the PI3K signaling pathway, and DPL is a promising novel therapeutic drug for NSCLC.
\end{abstract}

Correspondence to: Dr Xiu-Bao Ren, Department of Oncology, Tianjin Medical University Cancer Institute and Hospital, Beihuanhuxi Road, Hexi, Tianjin 300060, P.R. China

E-mail:renxiu_bao@163.com

${ }^{*}$ Contributed equally

Key words: diprophylline, proliferation, non-small cell lung, phosphoinositide 3-kinase signaling pathway, apoptosis

\section{Introduction}

Non-small cell lung cancer (NSCLC) is the leading cause of lung cancer-associated mortality (1). It has been reported that NSCLC constitutes nearly $90 \%$ of lung cancer (2). Since the majority of patients diagnosed with NSCLC are in an advanced stage, the therapeutic outcomes for NSCLC are not optimal (3). The use of chemotherapy has enhanced the treatment of NSCLC over the past 50 years (4). In particular, platinum-based chemotherapy, which is associated with improved survival, is currently the standard therapeutic treatment for patients with advanced NSCLC (5). However, a number of patients with NSCLC develop resistance to platinum-based chemotherapy, resulting in unsatisfactory treatment outcomes. It has also been reported that a number of molecules have anti-cancer effects on NSCLC, while few patients have advanced sites that are accessible via relatively non-invasive biopsy procedures (6). Therefore, it is necessary to develop novel chemotherapeutic drugs for the treatment of NSCLC.

Methylxanthine (MX) is a naturally occurring compound in animals and plants $(7,8)$. As reported in previous studies, MX may prevent the proliferation of a number of tumor cells, including oral cancer (9), breast cancer $(10)$ and lung cancer $(11,12)$. In addition, it has been demonstrated that caffeine, a class of MX, blocks the proliferation of hepatocellular carcinoma and pancreatic cancer cell lines by inhibiting the phosphoinositide 3-kinase (PI3K)/RAC- $\alpha$ serine/threonine-protein kinase (AKT) pathway (13). Similarly, theophylline, another MX derivative, possesses the capacity to inhibit the proliferation and migration of melanoma cancer cells (14). Diprophylline (DPL), known as a novel MX derivative with fewer adverse effects, is usually employed for relieving the clinical symptoms of and preventing bronchial asthma or other respiratory diseases $(15,16)$. In previous studies, there have been limited reports on the role of DPL in the treatment of cancer, particularly NSCLC (17). Therefore, it may be beneficial to investigate the ability of DPL to inhibit the cell proliferation and migration of A549 cells.

In the present study, the role of DPL in the growth, invasion, migration and apoptosis of NSCLC A549 cells was studied. Additionally, a potential molecular pathway was also detected following DPL treatment in A549 cells. 


\section{Materials and methods}

Cell culture. The human lung adenocarcinoma cell line A549 and normal human bronchial epithelial cells (HBEs) were purchased from the American Type Culture Collection (Manassas, VA, USA). The cells were incubated in RPMI-1640 (HyClone; GE Healthcare Life Sciences, Logan, UT, USA) supplemented with $10 \%$ fetal bovine serum (FBS; Gibco; Thermo Fisher Scientific, Inc., Waltham, MA, USA), penicillin $(100 \mathrm{U} / \mathrm{ml})$ and streptomycin $(0.1 \mathrm{mg} / \mathrm{ml})$. Cells were cultured at $37^{\circ} \mathrm{C}$ in an incubator containing $5 \% \mathrm{CO}_{2}$. Cells in the exponential growth phase $\left(\sim 1 \times 10^{6}\right.$ cells $\left./ \mathrm{ml}\right)$ were used for the following experiments.

Cell proliferation assay. Following the manufacturer's instructions, cell proliferation was determined using the Cell Counting Kit-8 (CCK-8; Beijing Solarbio Science \& Technology Co., Ltd., Beijing, China). Following culture for 72 h, A549 and HBE cells were treated with DPL (MedChemExpress USA, Monmouth Junction, NJ, USA) at varying concentrations $(0,0.1,1,10$ and $100 \mu \mathrm{M})$ with $0 \mu \mathrm{M}$ DPL as the control. In detail, $\sim 1 \times 10^{3}$ cells/well were seeded into 96-well plates and cultured in $100 \mu 1$ RPMI-1640 medium supplemented with 10\% FBS overnight. Based on the effects of different concentrations in the A549 and HBE cells, $10 \mu \mathrm{M}$ DPL was chosen as the effective concentration to be used in subsequent experiments. To exclude the effects of cell death on cell proliferation, migration, invasion and apoptosis, $1 \mu \mathrm{M}$ DPL was also added, in order to perform cell functional analysis, including cell proliferation, migration, invasion and apoptosis. Cells were incubated with 1 or $10 \mu \mathrm{M}$ DPL and $1 \%$ DMSO culture medium as the normal control group (NC). For performing the CCK-8 assay, $10 \mu$ l CCK-8 reagent was added to each well and the plates were incubated at $37^{\circ} \mathrm{C}$ for $1.5 \mathrm{~h}$. The cell viability was measured every $24 \mathrm{~h}$, and the optical density (OD) was measured at $450 \mathrm{~nm}$ using a microplate reader.

Transwell migration and invasion assay. Cell migratory and invasive abilities were assessed using 24-well Transwell chambers (EMD Millipore, Billerica, MA, USA) with membrane pore size of $8.0 \mu \mathrm{m}$. In detail, $100 \mu \mathrm{l}$ serum-free medium with $\sim 1 \times 10^{5}$ cells was plated in the upper chambers of the Transwell plates, while $500 \mu 1$ medium containing $10 \%$ FBS was added to the lower chamber. Following incubation at $37^{\circ} \mathrm{C}$ with $5 \% \mathrm{CO}_{2}$ overnight, non-migrating cells on the top chamber were scraped off with cotton-tipped swabs, and cells that had migrated through the membrane were fixed with $4 \%$ paraformaldehyde at room temperature for $30 \mathrm{~min}$. Cells were stained with $0.1 \%$ crystal violet at room temperature for $20 \mathrm{~min}$. Subsequently, the migrated cells were counted under a microscope at $\times 200$ magnification using five randomly selected visual fields. For cell invasion detection, Transwell membranes were precoated with Matrigel ${ }^{\circledR}$ (BD Biosciences, San Jose, CA, USA) at $37^{\circ} \mathrm{C}$ for $30 \mathrm{~min}$ prior to the experiment.

Flow cytometry apoptosis assay. Following the manufacturer's protocol, apoptotic A549 cells were evaluated using an Annexin V-fluorescein isothiocyanate (Annexin V-FITC)/propidium iodide (PI) Apoptosis Detection kit (Beijing 4A Biotech Co., Ltd., Beijing, China). A549 cells were treated with DPL and harvested by trypsinization without EDTA, washed twice with cold PBS, centrifuged at $560 \mathrm{xg}$ at $4^{\circ} \mathrm{C}$ for $5 \mathrm{~min}$ and the supernatant was discarded. The cell pellet was resuspended in $1 \mathrm{X}$ binding buffer and the cell density adjusted to $1-5 \times 10^{6}$ cells $/ \mathrm{ml}$. A total of $5 \mu 1$ FITC-conjugated Annexin $\mathrm{V}$ and $10 \mu \mathrm{l}$ PI were added and incubated for $5 \mathrm{~min}$ at room temperature in the dark. Following the addition of PI (10 $\mu \mathrm{l})$ and PBS (400 $\mu$ l), cells were analyzed using a flow cytometer and the data analyzed using FlowJo 7.6 software (FlowJo LLC, Ashland, OR, USA).

Western blot analysis. Following treatment with DPL or vehicle for $24 \mathrm{~h}$, total protein was extracted from cells using radioimmunoprecipitation assay buffer (CW Biotech, Co., Ltd., Beijing, China). Following lysis for $30 \mathrm{~min}$ on ice, the lysates were centrifuged at $13,400 \mathrm{x} \mathrm{g}$ at $4^{\circ} \mathrm{C}$ for $10 \mathrm{~min}$. The Bicinchoninic Acid Protein Assay kit (CW Biotech, Co., Ltd.) was used to determine the protein concentration. A total of $20 \mu \mathrm{g}$ protein/lane was separated via SDS-PAGE on an 8-10\% Tris-glycine gradient gel. Subsequently, the proteins were transferred onto a polyvinylidene diflouride membrane for $2 \mathrm{~h}$ and blocked with $5 \%$ non-fat milk in TBS containing $0.1 \%$ Tween-20 (pH 7.4) at room temperature for $1 \mathrm{~h}$. The membranes were incubated with primary antibodies (1:1,000 dilution) against AKT (ab18785), phosphorylated (p)-AKT (ab38449), serine/threonine-protein kinase mTOR (mTOR) (ab87540), p-mTOR (ab131538), Cyclin D1 (ab226977), p-ribosomal protein S6 kinase $\beta-1$ (p70S6K) (ab186753), apoptosis regulator Bcl-2 (Bcl-2) (ab196495), apoptosis regulator BAX (Bax) (ab53154) and active Caspase-3 (ab32042), and against GAPDH (1:5,000 dilution) (ab181603), at $4^{\circ} \mathrm{C}$ overnight, and were detected using goat anti-rabbit/mouse horseradish peroxidase-conjugated secondary antibodies (ab6721/ab6789, 1:5,000 dilution). Primary and secondary antibodies were from Abcam (Cambridge, MA, USA). Western blot bands were visualized using an enhanced chemiluminescence reagent system (PTG Company; USA) and were quantified using Quantity One 4.6.7 software (Bio-Rad Laboratories, Hercules, CA, USA).

Statistical analysis. Statistical analysis was performed using SPSS 18.0 (SPSS, Inc., Chicago, IL, USA) and GraphPad Prism 5 software (GraphPad Software, Inc., La Jolla, CA, USA). Measurement data are expressed as the mean \pm standard deviation. Means were compared using the Student's t-test and one-way Analysis of Variance (ANOVA). For one-way ANOVA, post hoc testing was performed using Dunnett's test. $\mathrm{P}<0.05$ was considered to indicate a statistically significant difference.

\section{Results}

DPL inhibits the proliferation of NSCLC A549 cells. The effect of DPL on the proliferation of A549 cells was analyzed using the CCK-8 assay. At concentrations of DPL $>10 \mu \mathrm{M}$, the viability of HBEs was inhibited (Fig. 1A). The viability of A549 cells was decreased in a dose-dependent manner at DPL $>1 \mu \mathrm{M}$ (Fig. 1B). Therefore, $10 \mu \mathrm{M}$ DPL was selected as the concentration to be used in subsequent experiments. To exclude the effect of cell death on cell proliferation, migration, invasion and apoptosis, experiments using $1 \mu \mathrm{M}$ DPL were also performed for cell functional analysis, including cell 

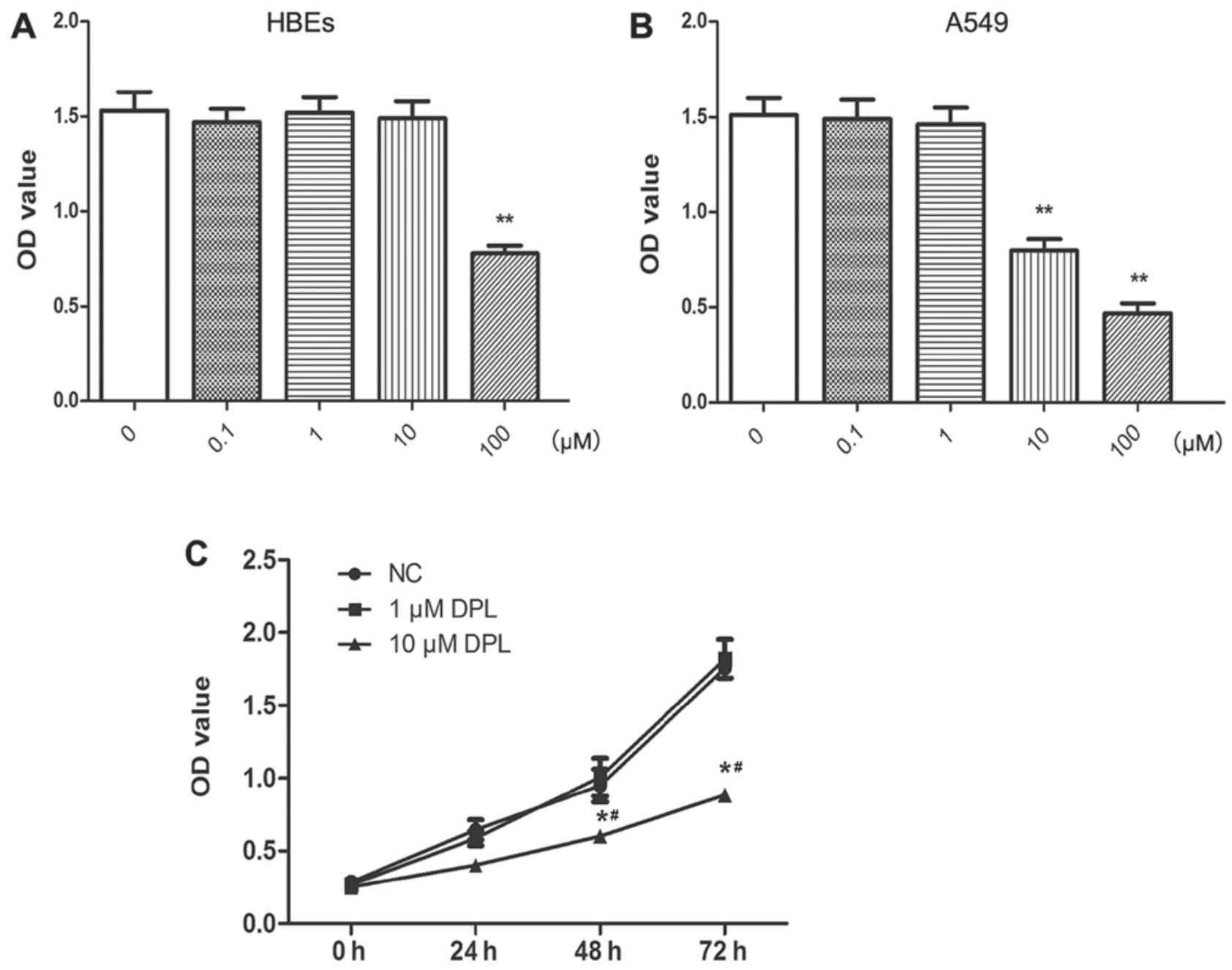

Figure 1. DPL is able to inhibit the proliferation of A549 cells. (A) OD values of A549 cells treated with gradient concentrations of DPL, measured by CCK-8 assay. (B) OD values of HBE cells treated with gradient concentrations of DPL, measured by CCK-8 assay. ${ }^{* *} \mathrm{P}<0.01$ vs. $0 \mu \mathrm{M}$ group. (C) Cell viability was determined by CCK- 8 assay for $0,24,48$ and $72 \mathrm{~h}$ following administration of 1 or $10 \mu \mathrm{M}$ DPL. Data are presented as the mean \pm standard deviation. ${ }^{*} \mathrm{P}<0.05$ vs. $1 \mu \mathrm{M}$ DPL; "P<0.05 vs. NC. DPL, diprophylline; NC, negative control; HBE, normal human bronchial epithelial cells; OD, optical density.

proliferation, migration, invasion and apoptosis. As presented in Fig. 1C, the proliferation of A549 cells treated with DPL decreased in a time-dependent manner, compared with the control group, and the OD values were significantly decreased at 48 and $72 \mathrm{~h}$, compared with the control $(\mathrm{P}<0.05)$. These results demonstrated that the proliferative abilities of A549 cells decreased notably following treatment with DPL.

DPL inhibits the migration and invasion of NSCLC A549 cells. Following $24 \mathrm{~h}$ treatment with DPL, Transwell assays were performed to determine the potential effect of DPL on cell migration and invasion in A549 cells. As presented in Fig. 2A, following treatment with $10 \mu \mathrm{M}$ DPL, the number of migrated cells was markedly decreased compared with the NC groups $(\mathrm{P}<0.05)$, while there were no detectable alterations in migrated cell numbers between the NC and $1 \mu \mathrm{M}$ DPL groups. Likewise, the invaded cell number in the group treated with $10 \mu \mathrm{M}$ DPL was significantly decreased compared with the NC group (Fig. 2B; P<0.05), while cells treated with $1 \mu \mathrm{M}$ DPL displayed no significant difference compared with the NC group. These results indicated that DPL may significantly inhibit migration and invasion in A549 cells.
DPL promotes the apoptosis of NSCLC A549 cells. To determine whether DPL could induce A549 cell apoptosis, Annexin-V-FITC/PI was used following $24 \mathrm{~h}$ treatment with DPL. The results demonstrated that the apoptosis rate in cells treated with $10 \mu \mathrm{M}$ DPL was significantly increased compared with the $\mathrm{NC}$ group (Fig. 3A; $\mathrm{P}<0.05$ ) while there were no detectable alterations between cells treated with $1 \mu \mathrm{M}$ DPL and the NC group (Fig. 3A; P>0.05). Subsequently, to study the mechanism mediating DPL-induced apoptosis, a western blot assay was used to determine the expression of Bcl-2, Bax and active caspase-3. The results demonstrated that following treatment with DPL, the expression level of the anti-apoptotic protein Bcl-2 was reduced, while the expression levels of the pro-apoptotic proteins Bax and active caspase- 3 were increased significantly (Fig. 3B; $\mathrm{P}<0.05$ ). The results confirmed that DPL may promote the apoptosis of A549 cells.

DPL inhibits the PI3K signaling pathway in NSCLC A549 cells. It has previously been demonstrated that the PI3K signaling pathway is a crucial in a variety of tumors and its key proteins, including AKT and mTOR, serve important roles in the proliferation and migration of tumors $(18,19)$. Therefore, a 


\section{A Migration}

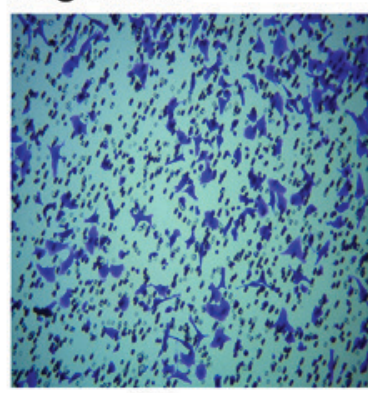

NC

\section{B Invasion}

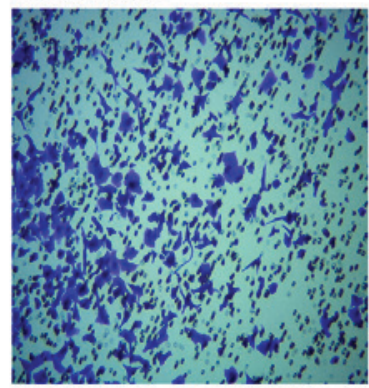

NC

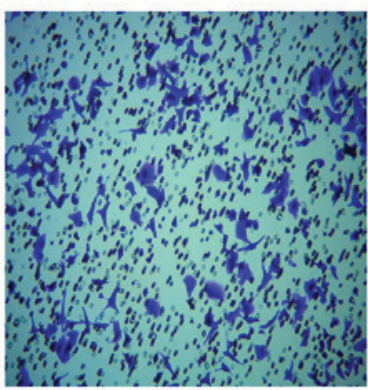

$1 \mu \mathrm{M}$ DPL

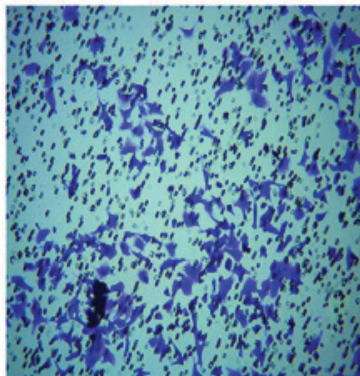

$1 \mu \mathrm{M}$ DPL

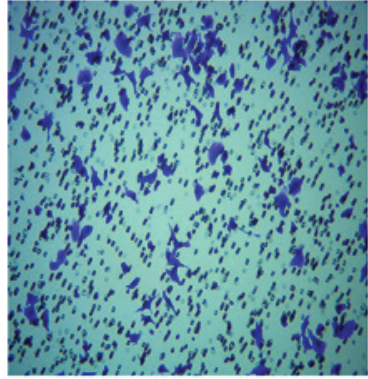

$10 \mu \mathrm{M} \mathrm{DPL}$
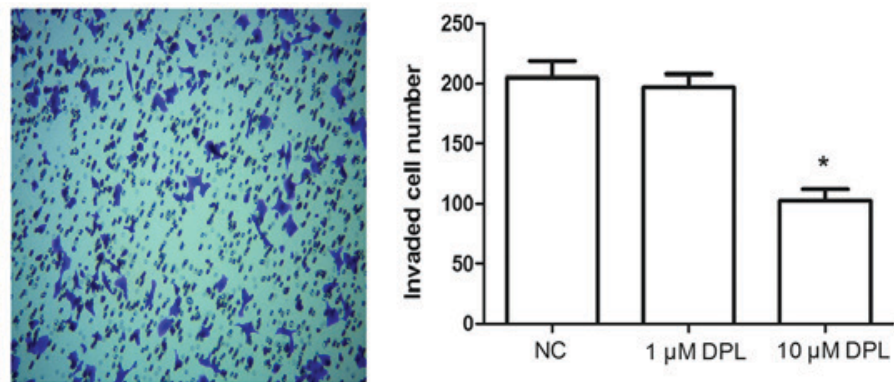

$10 \mu \mathrm{M}$ DPL

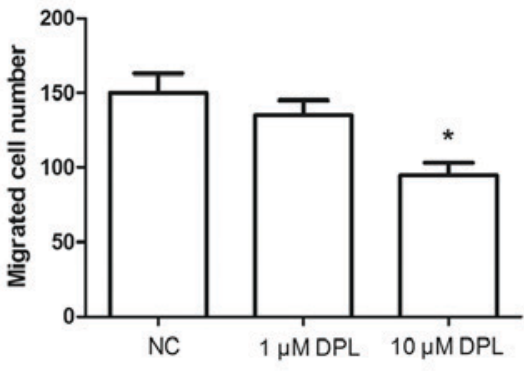

Figure 2. DPL inhibits the migration and invasion of A549 cells. Cell migration and invasion ability were measured by Transwell assay. Representative images of crystal violet-stained invasive cells are presented. (A) DPL notably reduced the number of cells migrating to the chamber. (B) DPL markedly reduced the number of cells invading the chamber. Data are presented as the mean \pm standard deviation. * $\mathrm{P}<0.05$ vs. NC. DPL, diprophylline; NC, negative control. $\mathrm{x} 200$ magnification.

A

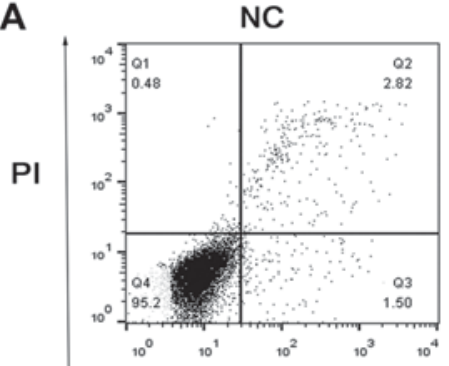

$1 \mu \mathrm{M}$ DPL

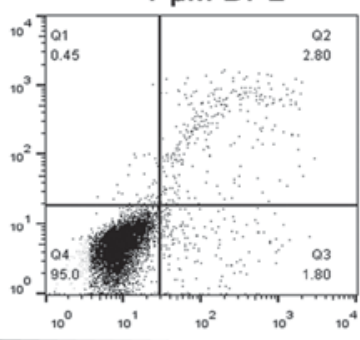

$10 \mu \mathrm{M} \mathrm{DPL}$

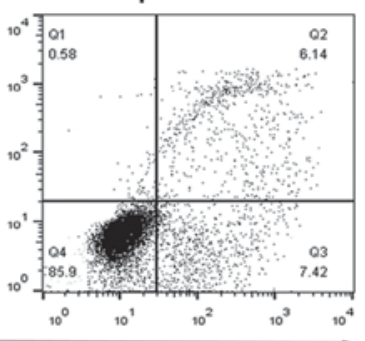

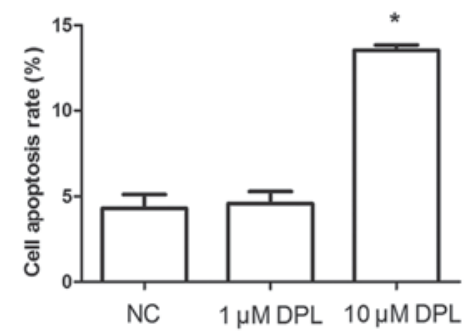

Annexin V FITC

B
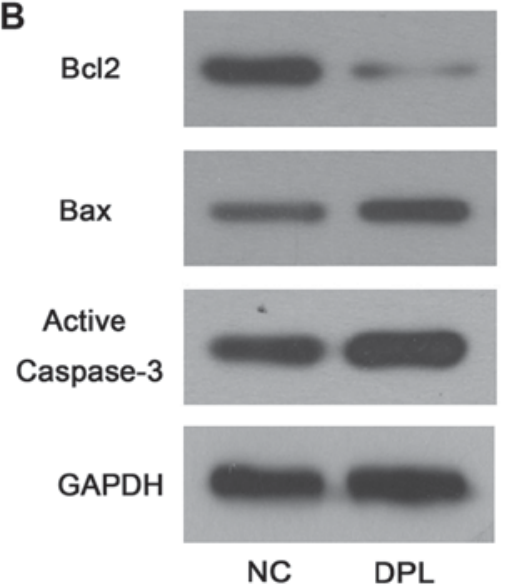
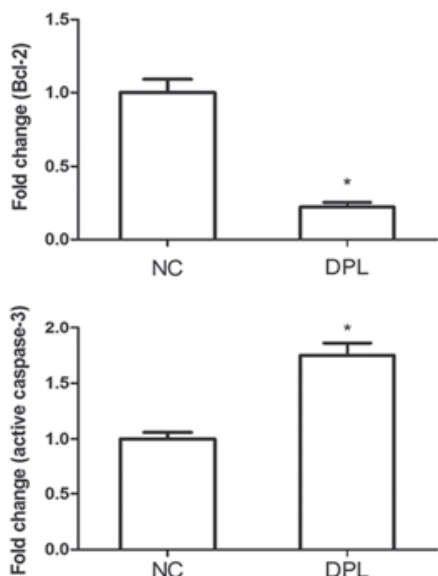

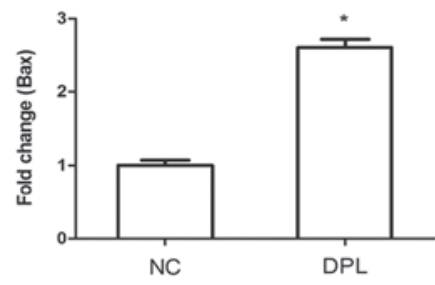

NC

DPL

Figure 3. DPL promotes the apoptosis of A549 cells. (A) The percentages of apoptotic cells were observed following staining with Annexin-FITC/PI via flow cytometry. The number of apoptotic cells was significantly increased following treatment with DPL. (B) Expression levels of the apoptosis-associated proteins including Bcl-2, Bax and active caspase- 3 were determined by western blot analysis. All data are presented as the mean \pm standard deviation. "P $<0.05$ vs. NC. DPL, diprophylline; NC, negative control; FITC, fluorescein isothiocyanate; Bcl-2, apoptosis regulator Bcl-2; Bax, apoptosis regulator BAX; PI, propidium iodide. 


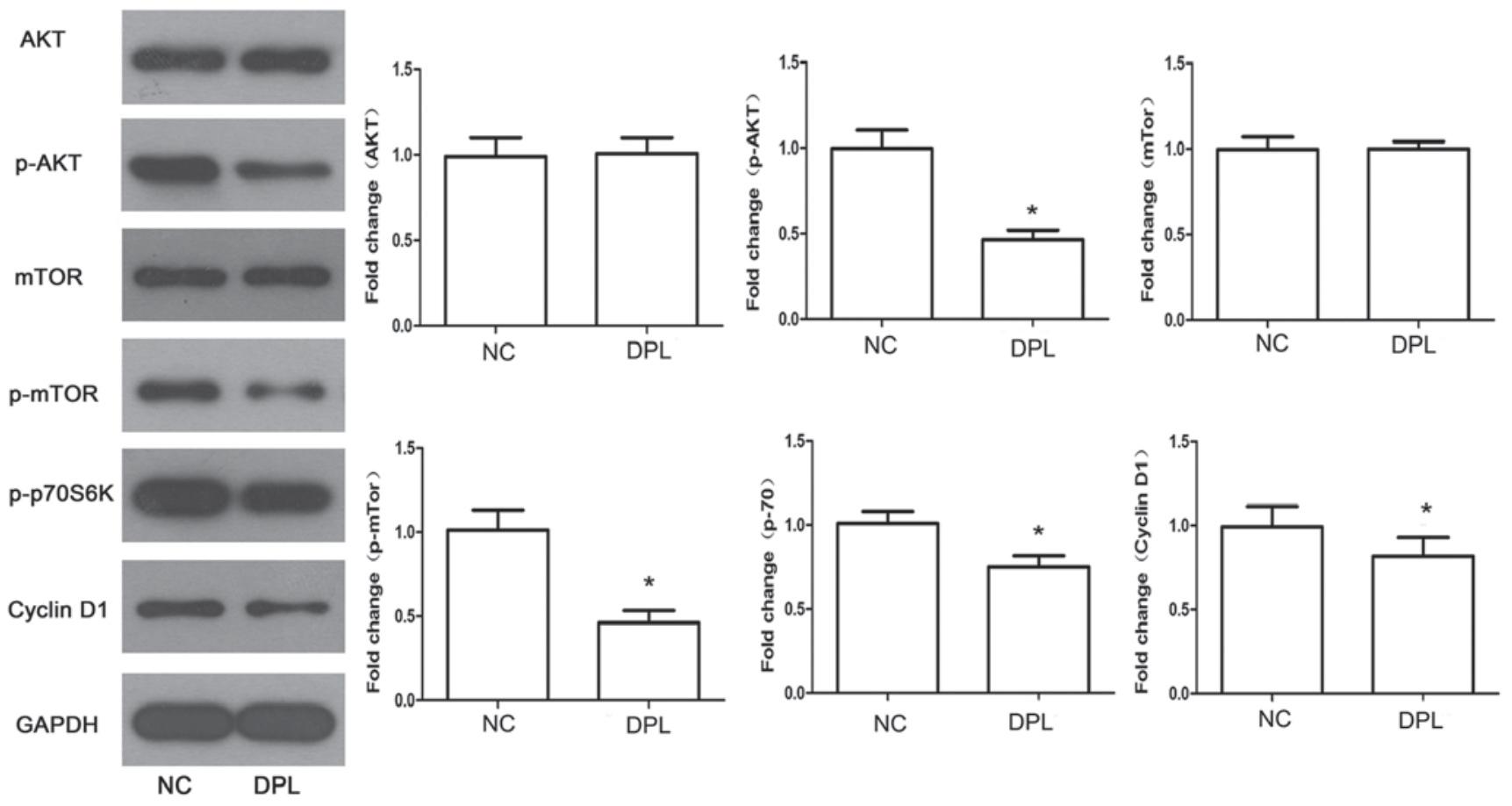

Figure 4. DPL downregulates the PI3K signaling pathway. The expression levels of key proteins associated with PI3K signaling, including AKT, p-AKT, mTOR, p-mTOR, p-p70S6K and Cyclin D1, were detected by western blot analysis. Data are presented as the mean \pm standard deviation. ${ }^{*} \mathrm{P}<0.05$ vs. NC DPL, diprophylline; NC, negative control; p, phosphorylated; AKT, RAC- $\alpha$ serine/threonine-protein kinase; mTOR, serine/threonine-protein kinase mTOR; p70S6K, ribosomal protein S6 kinase $\beta-1$.

series of specific key proteins were detected using western blot analysis, to determine the effect of DPL on the PI3K signaling pathway. As presented in Fig. 4, treatment of A549 cells with DPL led to a decrease in the phosphorylation levels of AKT and mTOR, yet there were no significant alterations in the total AKT and mTOR levels. The activity and expression levels of PI3K downstream molecules, including p-p70S6K and Cyclin D1, were reduced following treatment with DPL. Therefore, DPL may have the ability to downregulate the PI3K signaling pathway in A549 cells.

\section{Discussion}

In the present study, the potential therapeutic effect of DPL in NSCLC was studied. It was reported that DPL significantly inhibited A549 proliferation, migration and invasion, and induced apoptosis. In addition, it was revealed that the anti-tumor effect of DPL may be regulated through inhibition of the PI3K signaling pathway.

The ability of DPL to inhibit NSCLC A549 cell proliferation and metastasis is due to numerous mechanisms. Firstly, as a derivative of MX, DPL possesses a variety of pharmacological effects $(20,21)$. Additionally, DPL is a nonselective phosphodiesterase (PDE) inhibitor. PDE inhibitors have been reported to be used to treat tumor growth and migration, for example in NIH3T3 fibroblasts (22) and hepatocellular carcinoma cells (23). In the present study, it was demonstrated that DPL had anti-proliferative and anti-migratory effects in A549 cells. However, whether this effect is mediated via the MX pathway or the pathway of PDE inhibition requires further investigation. According to previous studies relating to DPL utilization in the clinic, DPL $(20 \mu \mathrm{M})$ exerts stimulatory effects on the contractility of jejunal segments in low-contractile states, and suppressive roles in high-contractile states (24). Additionally, according to the results of the present study, $10 \mu \mathrm{M}$ DPL was selected as the effective concentration for the majority of the experiments.

Apoptosis inhibits cancer cell survival. In the present study, it was reported that the expression levels of the anti-apoptotic protein $\mathrm{Bcl}-2$ were reduced, while the expression levels of the pro-apoptotic proteins Bax and active caspase- 3 were increased significantly, in cells treated with DPL. The results suggested that DPL may be involved in the regulation of apoptosis. It has been reported in recent years that PDE inhibitor regulation is one of a series of newly developed strategies in to explore targeted therapies in different types of cancer (25). In addition, Domvri et al (26) identified that the PDE inhibitors roflumilast and theophylline enhance apoptosis, thereby inhibiting tumor cell proliferation.

In the present study, the phosphorylation levels of AKT and mTOR were decreased and the activity and expression levels of the PI3K downstream molecules p-P70S6K and Cyclin D1 were reduced following treatment with DPL. It is widely reported that the deregulation of the PI3K signaling pathway is involved in the development of lung tumors and is associated with high-grade tumors and advanced disease (27). The regulation of PI3K signaling has been proposed as a potential therapeutic target in NSCLC. Mutations of numerous key factors in this pathway are associated with NSCLC (28) and four of the tested factors in this pathway, p-AKT, p-mTOR, p-p70S6K and Cyclin D1, may respond to the overexpression and knockdown of DPL. It may be that DPL is an inhibitor of the PI3K pathway, mediating cell invasion and apoptosis by regulating a number of the key factors in the PI3K pathway. 
In summary, the present study elucidated that DPL may inhibit A549 cell proliferation, migration and invasion, in addition to promoting apoptosis. DPL may regulate the expression levels of p-AKT, p-mTOR, p-p70S6K and Cyclin D1, and act as an inhibitor of the PI3K pathway. Therefore, DPL may be a promising novel drug for NSCLC treatment. However, there are limitations to this preliminary study; for example, further investigations into the underlying mechanisms of DPL may be beneficial, and the use of animal models may also be advantageous. Thus, further studies are required in the future.

\section{Acknowledgements}

Not applicable.

\section{Funding}

No funding was received.

\section{Availability of data and materials}

All data generated or analyzed during the present study are included in this published article.

\section{Authors' contributions}

XBR designed and performed the study and revised the manuscript. HYZ performed experiments and wrote the manuscript. YHR and YW performed experiments and analyzed the data. All authors have read and agreed the final manuscript.

\section{Ethics approval and consent to participate}

Not applicable.

\section{Patient consent for publication}

Not applicable.

\section{Competing interests}

The authors declare that they have no competing interests.

\section{References}

1. Lang Y, Kong X, He C, Wang F, Liu B, Zhang S, Ning J, Zhu K and Xu S: Musashil promotes non-small cell lung carcinoma malignancy and chemoresistance via activating the Akt signaling pathway. Cell Physiol Biochem 44: 455-466, 2017.

2. Molina JR, Yang P, Cassivi SD, Schild SE and Adjei AA Non-small cell lung cancer: Epidemiology, risk factors, treatment, and survivorship. Mayo Clinic Proc 83: 584-594, 2008.

3. Sakashita S, Sakashita M and Sound Tsao M: Genes and pathology of non-small cell lung carcinoma. Semin Oncol 41: 28-39, 2014.

4. Wakelee H, Kelly K and Edelman MJ: 50 years of progress in the systemic therapy of non-small cell lung cancer. Am Soc Clin Oncol Educ Book 34: 177-189, 2014.

5. Du L and Morgensztern D: Chemotherapy for advanced-stage non-small cell lung cancer. Cancer J 21: 366-370, 2015.

6. Hasegawa T, Sawa T, Futamura Y, Horiba A, Ishiguro T, Marui T and Yoshida T: Feasibility of rebiopsy in non-small cell lung cancer treated with epidermal growth factor receptor-tyrosine kinase inhibitors. Intern Med 54: 1977-1980, 2015.

7. Franco R, Oñatibia-Astibia A and Martínez-Pinilla E: Health benefits of methylxanthines in cacao and chocolate. Nutrients 5: 4159-4173, 2013.
8. Boison D: Methylxanthines, seizures, and excitotoxicity. Handb Exp Pharmacol: 251-266, 2011.

9. Zubairy YF, Patil VW, Benjamin T, Jangam D, Bijle MN and Patil S: Effect of methylxanthines (coffee/tea consumers) on oral precancer and oral cancer patients with smoking and smokeless tobacco habits. J Contemp Dent Pract 13: 745-758, 2012.

10. Goel PN and Gude RP: Unravelling the antimetastatic potential of pentoxifylline, a methylxanthine derivative in human MDA-MB-231 breast cancer cells. Mol Cell Biochem 358: 141-151, 2011.

11. Lange A, Gustke $\mathrm{H}$, Glassmeier $\mathrm{G}$, Heine $\mathrm{M}$, Zangemeister-Wittke U, Schwarz JR, Schumacher U and Lange T: Neuronal differentiation by indomethacin and IBMX inhibits proliferation of small cell lung cancer cells in vitro. Lung Cancer 74: 178-187, 2011.

12. Malki AM, Gentry J and Evans SC: Differential effect of selected methylxanthine derivatives on radiosensitization of lung carcinoma cells. Exp Oncol 28: 16-24, 2006.

13. Edling CE, Selvaggi F, Ghonaim R, Maffucci T and Falasca M: Caffeine and the analog CGS 15943 inhibit cancer cell growth by targeting the phosphoinositide 3-kinase/Akt pathway. Cancer Biol Ther 15: 524-532, 2014.

14. Lentini A, Kleinman HK, Mattioli P, Autuori-Pezzoli V, Nicolini L, Pietrini A, Abbruzzese A, Cardinali $M$ and Beninati S: Inhibition of melanoma pulmonary metastasis by methylxanthines due to decreased invasion and proliferation. Melanoma Res 8: 131-137, 1998.

15. Morais JA, Neves MC, Silva JR and Avila R: Absorption of intra-bronchial diprophylline-methodology and preliminary results. Eur J Drug Metab Pharmacokinet 17: 187-193, 1992.

16. Basnet RM, Zizioli D, Guarienti M, Finazzi D and Memo M: Methylxanthines induce structural and functional alterations of the cardiac system in zebrafish embryos. BMC Pharmacol Toxicol 18: 72, 2017.

17. Levi-Schaffer F and Touitou E: Xanthines inhibit 3T3 fibroblast proliferation. Skin Pharmacol 4: 286-290, 1991.

18. Polivka J Jr and Janku F: Molecular targets for cancer therapy in the PI3K/AKT/mTOR pathway. Pharmacol Ther 142: 164-175, 2014.

19. Martini M, De Santis MC, Braccini L, Gulluni F and Hirsch E: PI3K/AKT signaling pathway and cancer: An updated review. Ann Med 46: 372-383, 2014.

20. Lee IA,Kamba A,Low D and Mizoguchi E: Novel methylxanthine derivative-mediated anti-inflammatory effects in inflammatory bowel disease. World J Gastroenterol 20: 1127-1138, 2014.

21. Schoen K, Yu T, Stockmann C, Spigarelli MG and Sherwin CM: Use of methylxanthine therapies for the treatment and prevention of apnea of prematurity. Paediatr Drugs 16: 169-177, 2014.

22. Stork PJ and Schmitt JM: Crosstalk between cAMP and MAP kinase signaling in the regulation of cell proliferation. Trends Cell Biol 12: 258-266, 2002.

23. Ionta M, Rosa MC, Almeida RB, Freitas VM, Rezende-Teixeira P and Machado-Santelli GM: Retinoic acid and cAMP inhibit rat hepatocellular carcinoma cell proliferation and enhance cell differentiation. Braz J Med Biol Res 45: 721-729, 2012.

24. Liu FF, Chen DP, Xiong YJ, Lv BC and Lin Y: Characteristics of diprophylline-induced bidirectional modulation on rat jejunal contractility. Korean J Physiol Pharmacol 18: 47-53, 2014

25. Koiri RK, Mehrotra A and Trigun SK: Targetting cancer with Ru(III/II)-phosphodiesterase inhibitor adducts: A novel approach in the treatment of cancer. Med Hypotheses 80: 841-846, 2013.

26. Domvri K, Zarogoulidis K, Ziogas N, Zarogoulidis P, Petanidis S, Porpodis K, Kioseoglou E and Hohenforst-Schmidt W: Potential synergistic effect of phosphodiesterase inhibitors with chemotherapy in lung cancer. J Cancer 8: 3648-3656, 2017.

27. Scrima M, De Marco C, Fabiani F, Franco R, Pirozzi G, Rocco G, Ravo M, Weisz A, Zoppoli P, Ceccarelli M, et al: Signaling networks associated with AKT activation in non-small cell lung cancer (NSCLC): New insights on the role of phosphatydil-inositol-3 kinase. PLoS One 7: e30427, 2012.

28. Ding L, Getz G, Wheeler DA, Mardis ER, McLellan MD, Cibulskis K, Sougnez C, Greulich H, Muzny DM, Morgan MB, et al: Somatic mutations affect key pathways in lung adenocarcinoma. Nature 455: 1069-1075, 2008.

This work is licensed under a Creative Commons Attribution-NonCommercial-NoDerivatives 4.0 International (CC BY-NC-ND 4.0) License. 